\title{
Talk about Chinese contemporary literature classic construction based on external factors generated by classic literature
}

\author{
Li Chen \\ Department of Chinese Language and Literature \\ Pingdingshan Institute of Education \\ Pingdingshan, China
}

\begin{abstract}
The development process of literary history is always accompanied by changes in the evaluation of certain literary classics, as well as the process of shaping literary classics in each era. For modern and contemporary Chinese literature is concerned, a very prominent situation is that it has two different types of literary classics: one from the traditional time difference, the other from exotic spatial distance, two different literary classics have different demands, and the tension formed this contradiction constitutes motivation for the internal development of modern Chinese literature. It should also see the two literary classics in Chinese literature as the guiding force of the other side, and it is itself a two classic literature and evaluation system at this moment. Through the analysis of literary classics, you can see a side of literary development.
\end{abstract}

Keywords- literary classics; Chinese literature; cultural context; demonstration effect

\section{INTRODUCTION}

In recent years, China's contemporary literature attract more and more attention from foreign literary and academic area, and foreign literary and academic exchanges have become increasingly frequent, Chinese writers and scholars attended the International PEN and various international cultural events, many of the works and books have been translated and introduced to foreign countries, a large number of foreign writers and scholars come to China, or engage in literary communication, or engage in Chinese literature studying and researching. Some countries held a number of influential International discussions which is major on Chinese literature. In a number of International PEN or writing center activities, they also discussed the issue of Chinese Modern and Contemporary Literature. In recent years, China introduced or translated many foreign scholars' treatises and related materials in a variety of ways. In October 1986, the Chinese Writers Association held an international symposium in Shanghai; dozens of foreign scholar on Chinese Contemporary Literature participate in this activity, "Art News" Selected speeches of the seminar.

\section{A LITERARY CANON}

Literary Classics is one of the core content of literature, it is not just the most prominent representatives of the literary aspect, but the key lies in understanding the overall focus of literary classics involving literature, interpretation and evaluation, through the study of classics, in fact, it is an important way to get a glimpse of existing literature mechanism. If this understanding can be established, then the fact that today's Chinese literature classic has two different effects, first as a cultural tradition of Chinese classical literature, the second as a part of the impact of the literary concept of contemporary literary ideas imported from Western literature, techniques and methods. Two different set of classic literature have their own system, and these different systems constitute a contemporary classic literary background and basic contexts.

From academic perspective to examine the Classic construction of Chinese contemporary literature, it can be more fully seen the birth factor of literary classics .By examining the cultural discourse field, it can be seen that classic literature constantly being subverted and interpreted accompany with times' development. Classics of literature are often accompanied by the operation of national willpower, almost all in the form of education of the gradual completion of the classic. Based on the analysis of each angle anatomy of classical culture, this thesis simply discuss the mainstream values of humanity and charm made comes out of classical culture, and build raised alerts on modern and contemporary Chinese classic literature to a certain extent.

We often think why the classical literature was revered as a classic, it is internal blooming fascinating artistic charm, the charm of this art was once accepted, and it will be difficult to shake. However, with the changing of times and people's awareness and concept, making the classic culture is reinterpreted, each classic has its own cultural and respective field, which makes the classic culture are placed among an open system, and then be constantly rebuilt. Determine a literary classic, is not one of the words can chops, and it has become a classic of its internal inevitable exudes refreshing artistic charm, this charm continuously been commentaries and selection and spread by people as time goes by, it even undergoes testing by generation after generation in the long 
history, and finally be accepted and recognized by our people, and then elevated to a classical aesthetic value.

Anatomical national discourse on literary classic is not to say that the national discourse dominant everything nor elaborate literary scholars mediocrity. On the contrary, we should pay attention to this point; scholars played a subjective role in countries speak rights operation. Literary scholars can elaborate literary history, reflecting the effectiveness of its narrative, and thus impacting on the social and cultural groups in the unconscious, helping people build a sense of literary classics, so state power would go along with cultural potential and then prospect respected recognized classics in the national education. The so-called literary history, it presents the trajectory of the past, and its narrative is part of the modern description. Literary scholars have the right to select methods and narrative object of literature history, which leads to many scholars believe that their own choice is one of the words which accepted by public, it is very easy contrary to social readership recognized classics and narrative, and this will become a sensational act, it would seriously consume the credibility of literature researcher, so relevant scholars in this respect should particularly pay attention to this point.

\section{NARRATIVE CLASSIC CONSTRUCTIONS ON MODERN LITERATURE}

Reveal the relationship between the national discourse of literary classics and national power; we are not to say that the power of the national discourse can replace everything, nor to mean that literary scholars do nothing. Instead, the emphasis I concerned is how the scholars can play the subjective initiative in the operation of the national power of the mainstream discourse. Literary researchers may be able to pass the role of narrative and literary history of the collective unconscious to influence mainstream culture, so it can gradually form a list of literary canon (literary canon) in human mind, and promote the culture of state power to follow the trend of the times, and acclaim works of recognized classic writers in National Education.

Works which Lack of human spirit, pale thinking of poor writers can not become literary classics. Education as a national literary classic mainstream discourse material, the Nation need to be sure of making the textbook "emerged in an ideological and cultural hegemony," and literary historians also can not deny the aesthetic enlightenment role of literature. For example, Bing xin's work"Love Philosophy" has benefits on children psychological development, Su Qing's revenge feelings towards may contaminate young men and women, the former are likely to be constructed to become a classic, while the later is thought difficult to pave the way to classical studies. Seventh, the recent writers will not write history or comment in a hurry. It is dangerous for writers' works to set an example in a hurry without the test of time, without extensive comment. In the 20th century literature history which published in recent years, some of them definite the main current of the 1990s as a "great cultural prose" based on a writer's self-styled "Great cultural prose" and all its achievements and temporary effect publication, and then the author of this considerable controversy hailed as a classic of Chinese contemporary prose writers, it is very sloppy; not to mention"Cultural Revolution" set the newly created four literary works as "model". So there are many cases and enough to cause Paradox for the construction of contemporary classical literature. In this respect, modern literary family, literary scholars have the responsibility to do better, and it is also likely to play a bigger role in the literary canon. It should be noted that the literary classics of literature not all the literature, not all the works of outstanding writers, and even can say is not all the works of the most outstanding writers. As literary awards, as reflected in the mainstream discourse of literary classics of literature research and education, but not all, of literature research and education. When we look to take literary classics and non-classical writers, we should carefully obscure the value judgment of our literary studies influenced by mainstream cultural discourse power.

\section{FEATURES OF CHINESE MODERN AND CONTEMPORARY LITERATURE}

From the history of modern and contemporary Chinese literature, we can see that literature is developing along social development process, and modern and contemporary Chinese literature is in Chinese society violent agitation period, so there has heavy political imprint in literature. Compared with Chinese classical literature, we can see the limitations in the development path of modern and contemporary Chinese literature, watching over the political factors and neglect the natural creation of literature . Only when people live a social life in harmony with nature, we can achieve "Nature Unity ". In Chinese classical literature, a lot of works put emphasis on nature, but in contemporary literature it has been marginalized, and only a small amount of works only reflected this point, for example, Shen's "Border Town". It can be seen from four historical stages of the development of modern and contemporary Chinese literature, the literature works reflect the individual consciousness and the writer's personal values, so these literary works inevitably have some tilt, it is not so objective to describe the world or society according to their own imagination. In Modern and Contemporary Chinese Literature, there is almost only a kind of sound in a period of time, but the development of literature should be shining, flourishing instead of all writers express only a voice or a kind of desire. When entering the 1980s, the modern and contemporary Chinese literature began to have diversifying voices, literature showing a light shine. Criticize is the most attractive part in the study of contemporary literature, the infinite variety of literary phenomena and continually introduced new writers and works, not only linked with social life and cultural trends' beat, but also provides a new and non-repeated exciting, the creativity of criticism is also the most active in contemporary literary studies. So, many people put contemporary literature research equals to "status quo criticism". 
Chinese Modern and Contemporary Literature pioneering research will face the expansion of literature boundaries as well as cultural studies in the field of contemporary phenomenon in the development process of Chinese literature, and it has deeper hierarchy and changes towards the awareness of literature itself. In the whole environment of social development, there is a profit-oriented academic emotions and crowded study space extend to the superficial scholars. This leads to a model of the literary phenomenon in modern and contemporary Chinese literature, most literature has content standards, norms mode and other routines styles. There has been conflicting scene in contemporary literature studies, for one side showing a bustling scene of many achievements; the other side is showing the shallowness of academic content, the content were the same, and therefore has less influence and practical value. The Press prefers to publish books of Qian Zhongshu, Chang, Xu and other writers like them, but the real breakthrough and innovative researches of these writers' work are rare. In colleges and universities, contents which often regarded as academic achievements is only a "fast food culture" combines academic with public reading, they are stereotyped with little real academic achievement.

As time goes on, the history will become increasingly strict, even harsh in screening literature. Therefore, screening and interpretation of the classic nature was put on the agenda. In the new century, Modern and Contemporary Chinese Literature will become conscious and even be strengthened in grasping the depth of classic sense. What is a classic? What are the standards? This requires special study. But scholars have reached a consensus on the following issues: the classic is that part forever existing in readers' memory, which can stand the test of time. It is not popular, but more distant than popular; it is not one or two years' best seller, but long time enduring. A classic should be original in the art, it is resistant to read. Classic has rich connotation and profound revelation. Classic is relatively stable, but not immutable. Classic has its objective standard, not the public that goes. "Classic's academic value are judged by critics, while it's spread value are judged by readers" (1). And the study of Chinese Contemporary Literature is different from ancient Chinese literature study, its study history is short and time is closer, the selection and interpretation of the classic is far from complement, it is even just the beginning in some sense. In ancient Chinese novel study, it was argued temporarily "suspended classic", and returned to the living history of the novel phenomenon, because phenomenon has infinite richness.

\section{CONCLUSIONS}

On account of contemporary Chinese literature status, the author makes the following expectations. First, in narrative discourse of Chinese literature could appear more words which able to penetrate the life and soul. Second, Chinese writers shall abandon secular utilitarian consciousness, beyond the mediocre, and establish the truth and nature of mind and build the courage to explore the true meaning of life, and tap the essence of human nature in their own way to find the root cause of suffering, revealing the brutal burning of the Abyss human love. Third, the Chinese literary world can expect to see great works of novelty pierce the soul force in our time, we expect China can move towards real literature glory which has long been eager to.

\section{Reference}

[1] Liu Lian. writer, works on the study of the classics of modern literature significance - Meeting Summary "Chinese Modern and Contemporary Literature writer, works on the theory and methods of" [J] contemporary writers, 2012,04: 200- 202 + 124 .

[2] Wang Weiping. Modern Chinese Literature in the New Century New Century Prospects: the development of Chinese Modern and Contemporary Literature trend [J] Academic Monthly, 2002,03: 5-7.

[3] Zhang Zhizhong. from revolutionary to modernity magnificent turn now the paradigm of contemporary Chinese literature in the new period of 30 years to convert [A] Chinese Contemporary Literature Research, Shandong Normal University Chinese literature for 30 years. international Symposium of Chinese Contemporary Literature Research Society 15th annual Symposium Abstract Book [C] Chinese Contemporary Literature Research, Shandong Normal University: 2008: 1 .

[4] Cuiyan Qiu. Since the eighties contemporary Chinese fiction translation and dissemination in the United States[D].Jilin University, 2014.

[5] Chang Yung-wing cracks in two literary classics - Cultural Context of Contemporary Chinese Literature $[\mathrm{J}]$ Tsinghua University (Philosophy and Social Sciences), 2007,05: 31-38.

[6] Sun Chong contemporary Christian culture and values of Chinese literature [J] CPC Jinan Municipal Party College, 2005,01: 70-76.

[7] Yanghong Cheng Chinese Contemporary Literature Teaching How to Adapt university education reform [J] Jianghai Academic Journal, 2006,03: 196-199. 